\title{
Gasdynamic Model of Turbulent Combustion in TNT Explosions
}

A. L. Kuhl, J. B. Bell, V. E. Beckner

January 11,2010

33rd International Combustion Symposium 2010 Beijing, China August 1, 2010 through August 6, 2010 
This document was prepared as an account of work sponsored by an agency of the United States government. Neither the United States government nor Lawrence Livermore National Security, LLC, nor any of their employees makes any warranty, expressed or implied, or assumes any legal liability or responsibility for the accuracy, completeness, or usefulness of any information, apparatus, product, or process disclosed, or represents that its use would not infringe privately owned rights. Reference herein to any specific commercial product, process, or service by trade name, trademark, manufacturer, or otherwise does not necessarily constitute or imply its endorsement, recommendation, or favoring by the United States government or Lawrence Livermore National Security, LLC. The views and opinions of authors expressed herein do not necessarily state or reflect those of the United States government or Lawrence Livermore National Security, LLC, and shall not be used for advertising or product endorsement purposes. 


\title{
Gasdynamic Model of Turbulent Combustion in TNT Explosions
}

\author{
A. L. Kuhl ${ }^{1}$, J. B. Bell ${ }^{2}$, V. E. Beckner ${ }^{2}$ \\ ${ }^{1}$ Lawrence Livermore National Laboratory, P.O. Box 808, Livermore, CA 94551 USA \\ ${ }^{2}$ Lawrence Berkeley National Laboratory, 1 Cyclotron Rd, Berkeley, CA 94720 USA
}

\begin{abstract}
A model is proposed to simulate turbulent combustion in confined TNT explosions. It is based on: $(i)$ the multi-component gasdynamic conservation laws, (ii) a fast-chemistry model for TNT-air combustion, (iii) a thermodynamic model for frozen reactants and equilibrium products, (iv) a high-order Godunov scheme providing a non-diffusive solution of the governing equations, and $(v)$ an ILES approach whereby adaptive mesh refinement is used to capture the energy bearing scales of the turbulence on the grid. Three-dimensional numerical simulations of explosion fields from 1.5-g PETN/TNT charges were performed. Explosions in six different chambers were studied: three calorimeters (volumes of 6.6-1, 21.2-1 and 40.5-1 with $L / D=1)$, and three tunnels $(L / D=3.8,4.65$ and 12.5 with volumes of 6.3-1) - to investigate the influence of chamber volume and geometry on the combustion process. Predicted pressures histories were quite similar to measured pressure histories for all cases studied. Experimentally, mass fraction of products, $Y_{P}^{\exp }$, reached a peak value of $88 \%$ at an excess air ratio of twice stoichiometric, and then decayed with increasing air dilution; mass fractions $Y_{P}^{\text {calc }}$ computed from the numerical simulations followed similar trends. Based on this agreement, we conclude that the dominant effect that controls the rate of TNT combustion with air is the turbulent mixing rate; the ILES approach along with the fast-chemistry model used here adequately captures this effect.
\end{abstract}

Keywords: TNT Detonation Products, Turbulent Combustion, ILES, Barometric Calorimeter

\section{Introduction}

This paper describes the development of a gasdynamic model of turbulent combustion in confined TNT explosions. The particular problem under consideration is the blast wave formed by the detonation of a 1.5-g composite charge consisting of $0.5-\mathrm{g}$ spherical booster of PETN surrounded by a $1.0-\mathrm{g}$ spherical shell of TNT with initial densities of $\rho_{0}=1.0 \mathrm{~g} / \mathrm{cc}$. The charge was placed in the center of a chamber. Six chambers were used: cylindrical calorimeters A $\left(V_{c}=6.61, L=21 \mathrm{~cm}, D=20 \mathrm{~cm}\right.$,
$L / D=1.), \mathbf{B}\left(V_{c}=21.21, L=30 \mathrm{~cm}, D=30 \mathrm{~cm}\right.$, $L / D=1)$ and $\mathbf{C}\left(V_{c}=40.41, L=37.9 \mathrm{~cm}, D=36.9\right.$ $\mathrm{cm}, L / D=1)$, circular cross-section tunnel D ( $\left.V_{c}=6.31, D=12 \mathrm{~cm}, L=55.5 \mathrm{~cm}, L / D=4.65\right)$, and rectangular cross-section tunnels $\mathbf{E}$ ( $V_{c}=6.3$ 1, $X=Y=8 \mathrm{~cm}, L=100 \mathrm{~cm}, L / D=12.5)$ and $\mathbf{F}$ ( $V_{c}=41, X=Y=10.1 \mathrm{~cm}, L=38.6 \mathrm{~cm}, L / D=3.8$ ). The detonation of the charge created a blast wave that reflected off the chamber walls. The main diagnostic was Kistler 603B pressure gauges located on the lid of the calorimeters or end walls of the tunnels. Mixing of hot detonation products with air created a spherical 


\section{COMBUSTION IN TNT EXPLOSIONS}

combustion cloud, which enhanced the chamber pressure. A typical example of this combustion effect is shown in Fig. 1, which depicts pressure history measured for 1.5-g composite PETN/TNT charge detonated in air versus $\mathrm{N}_{2}$ (which suppresses combustion) atmospheres. Experimental results for 1.5-g composite PETN/TNT charges and PETN/Al charges were published in the $32^{\text {nd }}$ Int. Combustion Symposium [1]. Here we describe numerical modeling of those experiments.

Such combustion effects were first studied by Ornellas [2] in detonation calorimeter experiments. 25-g TNT charges were detonated in a 5.3-1 spherical bomb calorimeter; tests done in a vacuum measured the "Heat of Detonation, while tests done in $\mathrm{O}_{2}$ atmosphere measured the "Heat of Combustion". The temporal evolution of the combustion energy was studied by Kuhl and Reichenbach using the barometric calorimeter technique [3].

Previous numerical simulations include: gasdynmics of combustion of TNT products in air [4], afterburning of detonation products from $1-\mathrm{kg}$ TNT charges in $16-\mathrm{m}^{3}$ chamber [5], investigation of effects of confinement on combustion of TNT explosion products in air [6], and numerical simulations of thermobaric explosions [7]. In addition, a heterogeneous continuum model of $\mathrm{Al}$ particle combustion in explosions has been used to model the PETN/Al experiments [8].

Thermodynamic states in such combustion fields can be calculated by the Cheetah code developed by Fried [9]. In addition, Kuhl has found an analytic model for the turbulent combustion of TNT in a chamber, based on analysis in thermodynamic state space [10].

Presented here is a multi-component gasdynamic model of TNT combustion in explosions. The model details, along with the numerical methods used for integrating the governing equations are presented in $\$ 2$. Threedimensional numerical simulations were performed for 1.5-g PETN/TNT explosions in six chambers (A-F). Results are compared with experimental pressure histories in $\S 3$. This is followed by discussion of combustion efficiency in $\S 4$, and conclusion in $\S 5$.

\section{Model}

\subsection{Conservation Laws}

We consider an initial value problem starting at the time the detonation wave reaches the edge of the charge, so the detonation products are gases. We model the expansion of the detonation products and the ensuing blast waves that are created in the surroundings. We model the evolution of the combustion fields in the limit of large Reynolds and Peclet numbers, where effects of molecular diffusion and heat conduction are negligible. The flow field is governed by the following conservation laws:

$$
\begin{aligned}
& \partial_{t} \rho+\nabla \cdot(\rho \mathbf{u})=0 \\
& \partial_{t} \rho \mathbf{u}+\nabla \cdot(\rho \mathbf{u} \mathbf{u}+p)=0 \\
& \partial_{t} \rho E+\nabla \cdot(\rho \mathbf{u} E+p \mathbf{u})=0
\end{aligned}
$$

where $\rho$ and $\rho$ represent the gas density, pressure, $\mathbf{u}$ is the gas velocity vector, $E \equiv u+\mathbf{u} \cdot \mathbf{u} / 2$ denotes the total energy, and $u$ is the specific internal energy.

\subsection{Combustion Model}

We consider two fuels: PETN detonation products $\left(F_{1}\right)$ and TNT detonation products $\left(F_{2}\right)$, along with their corresponding combustion products: PETN-air $\left(P_{1}\right)$ and TNT-air $\left(P_{2}\right)$; their compositions are given in Tables 1 and 2 . We model the global combustion of both fuels $F_{k}$ with air $(A)$ producing equilibrium combustion products $P_{k}$ :

$F_{k}+A \Rightarrow P_{k} \quad(k=1$ or 2$)$ 
The mass fractions $Y_{k}$ of the components are governed by the component conservation laws:

$\partial_{t} \rho Y_{F k}+\nabla \cdot \rho Y_{F k} \mathbf{u}=-\dot{s}_{k}$

$\partial_{t} \rho Y_{A}+\nabla \cdot \rho Y_{A} \mathbf{u}=-\sum_{k} \alpha_{k} \dot{s}_{k}$

$\partial_{t} \rho Y_{P k}+\nabla \cdot \rho Y_{P k} \mathbf{u}=\sum_{k}\left(1+\alpha_{k}\right) \dot{s}_{k}$

Fuel and air are consumed in stoichiometric proportions: $\alpha_{k}=A / F_{k}$. In the above, $\dot{s}_{k}$ represents the global kinetics sink term. In this work we use the fast-chemistry limit that is consistent with the inviscid gasdynamic model (1)-(3), so whenever fuel and air enter a computational cell, they are consumed in one time step.

\subsection{Equations of State}

Our code carries the density and specific internal energy, along with the gas composition in each cell. These are used to calculate the pressure and temperature in a computational cell based on Equations of State (EOS). The thermodynamic states encountered during SDF explosions have been analyzed in [11]. Here we summarize only the salient features needed for the present numerical modeling.

Figures 2 and 3 present the locus of states in the Le Chatelier diagram of specific internal energy versus temperature $(u-T)$. Presented in Fig. 2 are curves for reactant components: PETN detonation products (PETN), TNT detonation products $(T N T)$ and air $(A)$; their corresponding equilibrium combustion products $\left(P_{k}\right)$ are depicted in Fig. 3. In this formulation, combustion becomes:

\section{material transformations from Reactants $\rightarrow$ Products at constant energy}

resulting in combustion temperatures of $3,175 \mathrm{~K}$ and 2,900 K for PETN-air and TNT-air systems, respectively (see Fig. 3). The system is isoenergetic - so there is no energy addition (e.g., "Heat of Combustion") in the energy conservation equation (3). In a reacting cell, before combustion, the reactants EOS are used; after combustion, the products EOS are used.

In [11] we have shown that these components behave as calorically-perfect gases for $T<3,500 \mathrm{~K}$. Thus it is appropriate to fit them solely as a function of temperature. Piecewise quadratic functions were used to define the components $c$ :

$$
u_{c}(T)=a_{c} T^{2}+b_{c} T+c_{c}
$$

for $c=A, F_{k}, P_{k}$. Given $u_{c}$, one can solve the quadratic to find the temperature. Then for a pure cell, the pressure is computed from the perfect gas law:

$p_{c}=\rho_{c} R_{c} T_{c}$

or from the JWL function in the detonation products gases [11]:

$$
\begin{aligned}
p_{J W L}(v, T) & =A\left(1-\frac{\omega \cdot v_{0}}{R_{1} \cdot v}\right) e^{-R_{1} \cdot v / v_{0}} \\
& +B\left(1-\frac{\omega \cdot v_{0}}{R_{2} \cdot v}\right) e^{-R_{2} \cdot v / v_{0}}+R T / v
\end{aligned}
$$

where $v$ is the specific volume $(v=1 / \rho)$. For mixed cells, the caloric equation of state retains the same form as (8), but the coefficients are weighted by the mass fraction of components in the cell. See [11] for more details and fitting constants.

\subsection{Numerical Methods}

The governing equations (1)-(3) and (5)-(7) were integrated with a high-order Godunov scheme based on an efficient Riemann solver 


\section{COMBUSTION IN TNT EXPLOSIONS}

for gasdynamics first developed by Colella and Glaz [12] and extended to generalized conservation laws by Bell et al. [13]. The solver was modified to accommodate negative specific internal energies (vid. Fig. 2 and 3) associated with our thermodynamic formulation. In this approach, information propagates along characteristics at the correct wave speeds, and it incorporates nonlinear wave interactions within the cell during the time step. The methodology includes a limiting step (slope flattening) that automatically reduces the order of approximation in the neighborhood of discontinuities, while in smooth regions of the flow the scheme is second order in time and space.

The Godunov scheme has been incorporated into an adaptive mesh refinement (AMR) algorithm that allows one to focus computational effort in complex regions of the flow such as mixing layers and reaction zones. Our adaptive methods are based on the blockstructured AMR algorithms of Berger \& Colella [14], and extended to three-dimensional hyperbolic systems by Bell et al. [15]. Embedded boundary methods are used to represent irregular geometries [16]. In this AMR approach, regions to be refined are organized into rectangular patches, with several hundred to several thousand grid-points per patch. One can refine based on discontinuities (shocks and contact surfaces), using Richardson error estimates, or for present purposes, on flame surfaces.

\subsection{Turbulent Mixing}

AMR is also used to refine turbulent mixing regions; by successive refinements we are able to capture the energy-bearing scales of the turbulence on the computational grid. In this way we are able to compute the effects of turbulent mixing without resorting to explicit turbulence modeling. This is consistent with the so-called MILES (Monotone Integrated LargeEddy Simulation) approach of Boris [17]. A comprehensive review of implicit Large-Eddy
Simulation (iLES) methods may be found in Grinstein et al [18]. A verification of the ability of our Godunov scheme to replicate the Kolmogorov spectrum of turbulent flows has been demonstrated by Aspden et al [19].

\subsection{Initial Value Problem}

We assume that the charge is consumed by a constant velocity Chapman-Jouguet (CJ) detonation wave. Therefore we initialize the computational grid with the self-similar flowfield corresponding to a spherical CJ detonation wave of Taylor [20] when the detonation reaches the edge of the charge. Initially we use six levels of AMR grid refinement-to resolve the initial wave structure, and then drop refinement levels as the blast wave expands.

\section{Results}

Evolution of the flowfield engendered by the detonation of a 1.5 -g PETN/TNT charge was computed with the 3-d AMR code. We start with numerical simulations of the un-confined case, which will be used for flow visualization of the mixing ( $\S 3.1$ ), and then move on to simulations of combustion in chambers A-F. Results will be compared with experimental pressure and impulse histories in $\$ 3.2$ and $\$ 3.3$. The latter will be used to establish mean chamber pressures and combustion completeness.

\subsection{Flow Visualization}

In Fig. 4 we present a cross-sectional views of the evolution of the flow field created by the detonation of a 1-g spherical TNT charge in an unconfined space. Composition of the flow field is represented by colors: fuel is yellow, air is blue and combustion products are red. White dots denote the cells that are burning during the current computational cycle. Black lines represent contours of $\nabla \cdot \mathbf{u}$ thereby making shocks visible, while green contours denote $\nabla \times \mathbf{u}$ thereby making vorticity visible. One can see that the detonation products-air interface is 
unstable and develops Richtmyer [21]-Meshkov [22] mixing structures with high vorticity. One can also see the spherical shock forming the blast wave in air, and an imploding shock in the detonation products (DP) gases. By $114 \mu \mathrm{s}$, the imploding shock has reached the center $(r=0)$; thereafter it propagates back through the $D P$ gases (times 161 $\mathrm{s}$ and $221 \mu \mathrm{s}$ ), and then emerges from the $D P$ cloud forming a second blast wave discovered by Brode [23]. This imploding shock draws the mixing structures in towards the center $(114 \mu \mathrm{s})$ forming Taylor cavities [24,25]; Kelvin [26]-Helmholtz [27] structures are visible on the cavity walls. The vorticity in these cavities mixes the air with the fuel, forming hot $(2,900 \mathrm{~K})$ combustion products. Similar mixing structures are seen in experiments: Fig. 5 presents a shadow photograph visualization of mixing inside the fireball from a PETN/TNT $(0.5 \mathrm{~g} / 1 \mathrm{~g})$ charge; Taylor cavities are prominent. An exterior view of the combustion products interface from an AMR code simulation is presented in Fig. 6, which shows numerous mushroom-capped structures.

\subsection{Pressure Histories}

Pressure histories from numerical simulation of the 3-d combustion field in chambers A-F are presented in Fig. 7. These are compared with pressure histories measured at $r$ $=5 \mathrm{~cm}$ on the lid of cylindrical calorimeters AC of different volumes $(L / D=1)$, and the endwall of the tunnels D-F of different $L / D$ ratios. Computed waveforms are quite similar to measured waveforms - judged on the basis of initial shock arrival time, peak pressure and waveform, and subsequent shock arrival times, peak pressures and waveforms. Agreement of various shock arrival times indicates that the temperature/sound speed fields computed for combustion of PENT/TNT with air similar to the experimental fields.

\subsection{Chamber Pressures}

Pressure histories from Fig. 7 were integrated to compute the impulse:

$$
I_{k}(t)=\int_{1 m s}^{3 m s} \Delta p_{k}\left(t^{\prime}\right) d t^{\prime}
$$

during $1<\mathrm{t}(\mathrm{ms})<3$. The impulse histories were fit with linear functions of time: $p(t)_{f i t}=a+\Delta \bar{p}_{c} \cdot t$; the slope then represents the mean chamber pressure, $\Delta \bar{p}_{c}$ (vid. Table 3). The so established mean chamber pressures from the computations are depicted as a function of chamber volume: $V_{c}$ in Fig. 8 (for $L / D=$ constant) and as a function of $L / D$ (at $V_{c}=$ constant) in Fig. 9. They are similar to values inferred from the measured pressure histories [3]. Both are somewhat less than the theoretical values predicted for a Constant Volume Explosion (CVE) in a chamber (Fig. 8). Both diverge more and more from the $p_{C V E}$ as $L / D$ increases (Fig. 10) because the tube confinement suppresses mixing and combustion.

\section{Discussion}

According to theory of combustion in a thermodynamically-isolated chamber [10], the mass-fraction of combustion products at late times $\left(Y_{P}^{\infty}\right)$ is related to mean chamber pressures by the relation:

$Y_{P}^{\infty}=\left[\bar{p}_{c}^{\infty}-p_{R}\right] /\left[p_{P}-p_{R}\right]$

where $p_{R}$ and $p_{P}$ denote the chamber pressures predicted for frozen reactants $R$ and equilibrium combustion products $P$ (corresponding to $\mathrm{CVE}$ explosions computed by the Cheetah code). Results are compiled in Table 3 and presented in Fig. 10 as a function of excess air ratio: $\chi=\alpha_{\text {chamber }} / \alpha_{\text {stoich }}$ (corresponding to chambers A-C and F). Combustion products mass-fraction reaches a peak value of $88 \%$ for air concentrations about twice stoichiometric $(\chi \approx 2)$, and then decay as air dilution increases. Presumably this is due to quenching by the cold excess air. The mass-fraction of combustion products computed from the numerical simulations (at $t=3 \mathrm{~ms}$ ) follows similar trends, 


\section{COMBUSTION IN TNT EXPLOSIONS}

but their values are about $10 \%$ lower than the experimental values (see Table 3 ).

\section{Conclusions}

A gasdynamic model has been proposed for numerical simulations of turbulent combustion of detonation products gases with air. It is based on the following elements: $(i)$ the multi-component gasdynamic conservation laws, (ii) a combustion model utilizing the fastchemistry limit, (iii) a thermodynamic model assuming frozen reactants and equilibrium products, (iv) a high-order Godunov scheme providing non-diffusive solutions to the conservation laws, and (v) adaptive mesh refinement algorithm to capture the energybearing scales of the turbulent mixing. Pressures histories from the numerical simulations were quite similar to measured pressure histories for all cases studied (chambers $\mathbf{A}-\mathbf{F}$ ). The model was able to capture the influence of chamber volume and geometry on the global fuel consumption; numerical results followed trends similar to the experiments in regard to massfraction of products versus excess air ratio: $Y_{P}^{\infty}(\chi)$. Based on this agreement, we conclude that the dominant effect that controls the rate of TNT combustion with air is the turbulent mixing rate; the ILES approach along with the fast-chemistry model used here adequately captures this effect in the high turbulent post blast wave environment studied here.

\section{Acknowledgements}

This work performed under the auspices of the U.S. Department of Energy by Lawrence Livermore National Laboratory under Contract DE-AC52-07NA27344.

\section{References (363 words)}

[1] A. L. Kuhl, H. Reichenbach, Proc. Comb. Inst. 32:2 (2009) 2291-2298.

[2] D. L. Ornellas, LLNL Report No. UCRL52821 (1982) 1-80.

[3] A. L. Kuhl, Reichbach, Barometric

calorimeters, Khimicheskaya Fizika (in press)
[4] A. L. Kuhl, R. E. Ferguson, A. K. Oppenheim, Archivum Combustionis 19:1-4 (1999) 67-89.

[5] A. L. Kuhl, J. W. Forbes, J. B. Chandler, $34^{\text {th }}$ Int. Annual Conf. of ICT (2003) 9.1-9.14.

[6] A. L. Kuhl et al., Archivum Combustionis 21:1 (1999) 3-25.

[7] A. L. Kuhl, J. B. Bell, V. E. Beckner, B. Khasainov, $38^{\text {th }}$ Int. Annual Conf. of ICT (2007) 1.1-1.14.

[8] A. L. Kuhl, J. B. Bell, V. E. Beckner, Heterogeneous continuum model of $\mathrm{Al}$ particle combustion in explosions, Fizika Goreniya I Vzryva (in press)

[9] L. E. Fried, CHEETAH 1.22 User's Manual, Report No. UCRL-MA-117541 (1995).

[10] A. L. Kuhl, ХИМИУЕСКАЯ ФИЗИКА 25:10 (2006) 42-48.

[11] A. L. Kuhl, B. Khasainov, $38^{\text {th }}$ Int. Annual Conf. of ICT (2007)143.1-143.11.

[12] P. Colella, H. M. Glaz, J Comp. Phys. 59 (1985) 264-289.

[13] J. B. Bell, P. Colella, J. A. Trangenstein, J Comp. Phys. 92:2 (1989) 362-397.

[14] M. J. Berger, P. Colella J Comp. Phys. 82:1 (1989) 64-84.

[15] J. B. Bell, M. Berger, J. Saltzman, M. Welcome SIAM J Sci. Statist. Comput. 15:1 (1994) 127-138.

[16] R. B. Pember et al, J Comp. Phys. 120:2 (1995) 278-304.

[17] J. P. Boris Lecture Notes in Physics 257 Springer-Verlag, Berlin (1989) 344-353.

[18] F. F. Grinstein et al. Implicit Large-Eddy Simulation: Computing Turbulent Fluid Dynamics, Cambridge University Press (2007) 546.

[19] A. J. Aspden et al, Com. App. Math. Comp. Science 3 (2008) 103-126.

[20] G. I. Taylor, Proc. Roy. Soc. London A200 (1950) 235-247. 
[21] R. D. Richtmyer, Comm. Pure Appl. Math. 13 (1960) 297-319.

[22] E. E. Meshkov, Izv AN SSRE Mekanika Zhidkosti i Gaza 4:15 (1960) 151-157.

[23] H. L. Brode Phys. Fluids 2:2 (1959) 217229.

[24] G.I. Taylor, Proc. R. Soc. London, A201 (1950) 192-196.

[25] Lord Rayleigh, Lord, Proc. London Mat. Society 14 (1883) 170-177.

[26] Lord Kelvin, Phil. Magazine 42 (1871) 362-377.

[27] H. L. F. von Helmholtz, Monatsberichte der Königlichen Preussische Akademie der Wissenschaften zu Berlin 23 (1868) 215.

Table 1. Composition (moles/kg) of frozen reactants

\begin{tabular}{|c|c|c|c|c|c|c|}
\hline Fuel & $\mathrm{H}_{2} \mathrm{O}$ & $\mathrm{CO}_{2}$ & $\mathrm{~N}_{2}$ & $\mathrm{CO}$ & $\mathrm{CH}_{4}$ & $\mathrm{H}_{2}$ \\
\hline PETN & 11.5 & 10.7 & 6.3 & 5.2 & - & 1.1 \\
\hline TNT & 3.6 & 6.0 & 6.8 & 10.8 & 2.9 & 1.1 \\
\hline
\end{tabular}

Table 2. Composition (moles/kg) of stoichiometric equilibrium products

\begin{tabular}{|c|l|l|l|l|l|}
\hline Fuel & $\mathrm{H}_{2} \mathrm{O}$ & $\mathrm{CO}_{2}$ & $\mathrm{~N}_{2}$ & $\mathrm{O}_{2}$ & $\mathrm{CO}$ \\
\hline PETN-air & 7.6 & 6.1 & 12.8 & 2.3 & 4.6 \\
\hline TNT-air & 2.4 & 5.1 & 22.3 & 1.1 & 2.0 \\
\hline
\end{tabular}

Table 3. Chamber pressures and mass-fraction of products

\begin{tabular}{|c|c|c|c|c|c|}
\hline Case & $\begin{array}{c}\bar{p}_{C V E}^{*} \\
\text { bars }\end{array}$ & $\begin{array}{c}\bar{p}_{\text {exp }}^{*} \\
\text { bars }\end{array}$ & $\begin{array}{c}\bar{p}_{\text {calc }}^{*} \\
\text { bars }\end{array}$ & $\begin{array}{c}Y_{P, \exp } \\
(\%)\end{array}$ & $\begin{array}{c}Y_{P, \text { calc }} \\
(\%)\end{array}$ \\
\hline $\mathrm{A}$ & 8.94 & 8.37 & 7.65 & 88.4 & 73.6 \\
\hline $\mathrm{B}$ & 3.98 & 3.52 & 3.24 & 70.9 & 53.4 \\
\hline $\mathrm{C}$ & 2.64 & 2.13 & 2.17 & 39.3 & 45.1 \\
\hline $\mathrm{D}$ & 9.36 & 7.04 & 6.49 & 54.4 & 43.6 \\
\hline $\mathrm{E}$ & 9.36 & 5.44 & 5.84 & 22.9 & 30.7 \\
\hline $\mathrm{F}$ & 12.1 & 10.1 & 9.12 & 68.2 & 51.8 \\
\hline
\end{tabular}

* $\bar{p}_{c}=p_{a}+\Delta p$ where $p_{a}=0.978$ bars

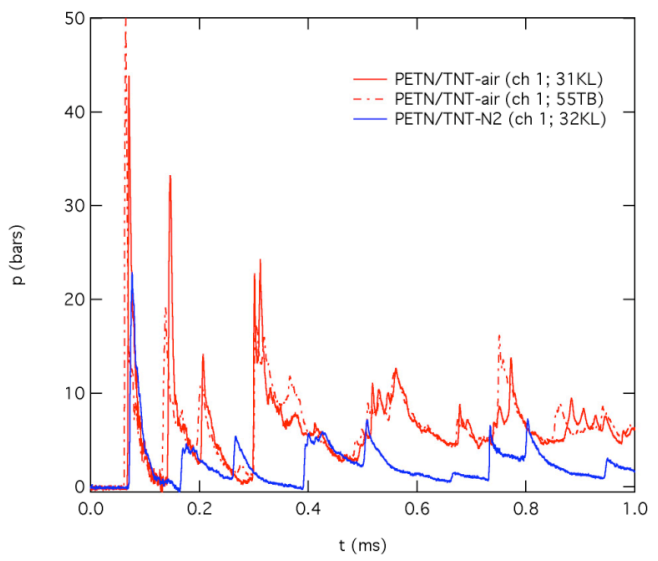

Figure 1. Comparison of pressure histories measured in calorimeter $\mathrm{A}$, for a $1.5-\mathrm{g}$ PETN/TNT charge detonated in air versus $\mathrm{N}_{2}$ atmospheres.

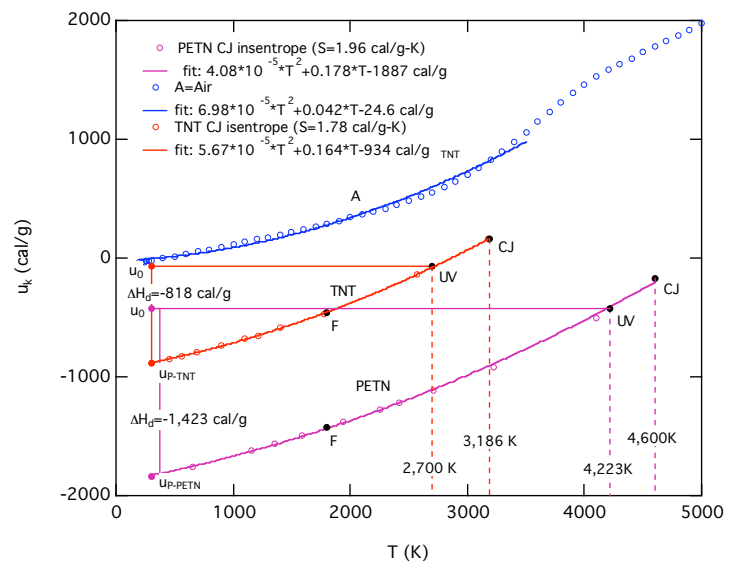

Figure 2. Detonation products isentropes for TNT and PETN charges $\left(\rho_{0}=1 g / c c\right)$, with frozen Products composition for $\mathrm{T}<1,800 \mathrm{~K}$.

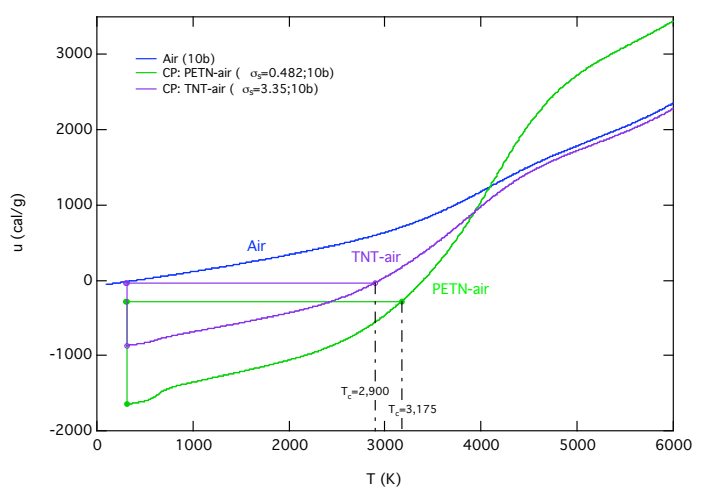

Figure 3. Combustion Products (CP) loci for stoichiometric mixtures of TNT-air $\left(\sigma_{s}=3.35\right)$ and PETN-air $\left(\sigma_{s}=0.482\right)$. Horizontal lines represent adiabatic combustion. 


\section{COMBUSTION IN TNT EXPLOSIONS}

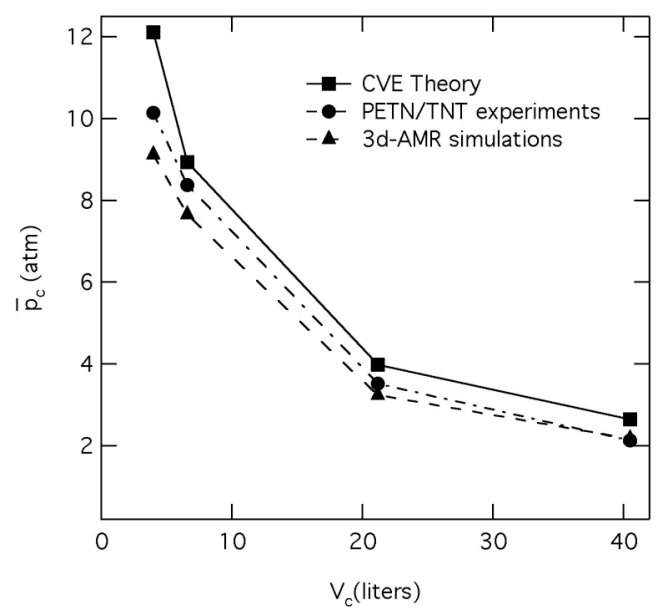

Figure 8. Comparison of mean chamber pressures with thermodynamic predictions of Constant-Volume-Explosions (CVE) as a function of chamber volume $V_{c}(L / D=1)$.

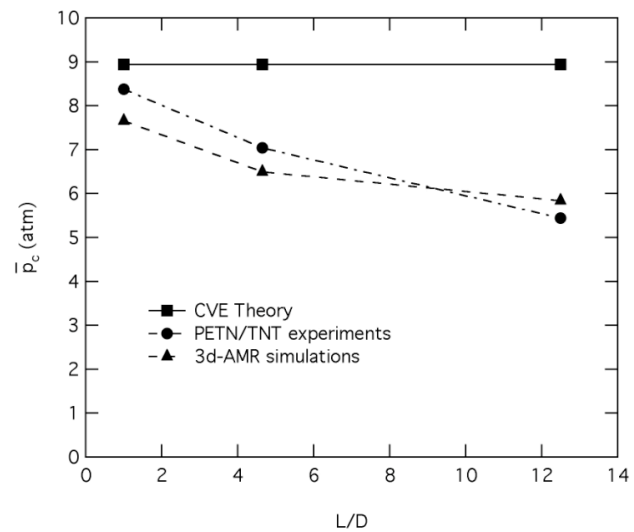

Figure 9. Comparison of mean chamber pressures with thermodynamic predictions of Constant-Volume-Explosions (CVE) as a function of tunnel $L / D\left(V_{c}=6.3\right.$ liters $)$.

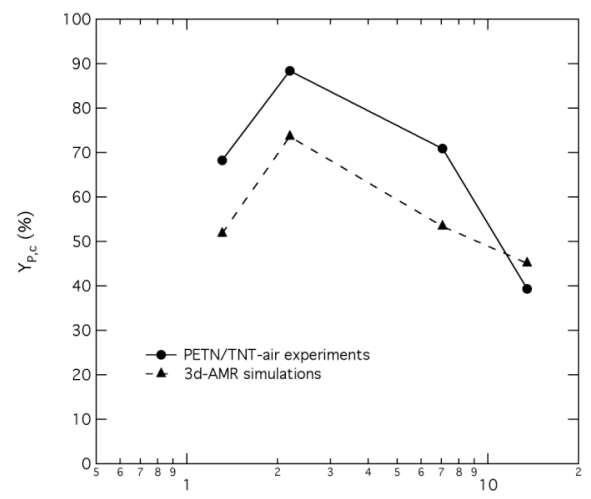

Figure 10. Mass fraction of combustion Products $Y_{p, c}$ as a function of $\chi$. 
COLOR PLATE 1

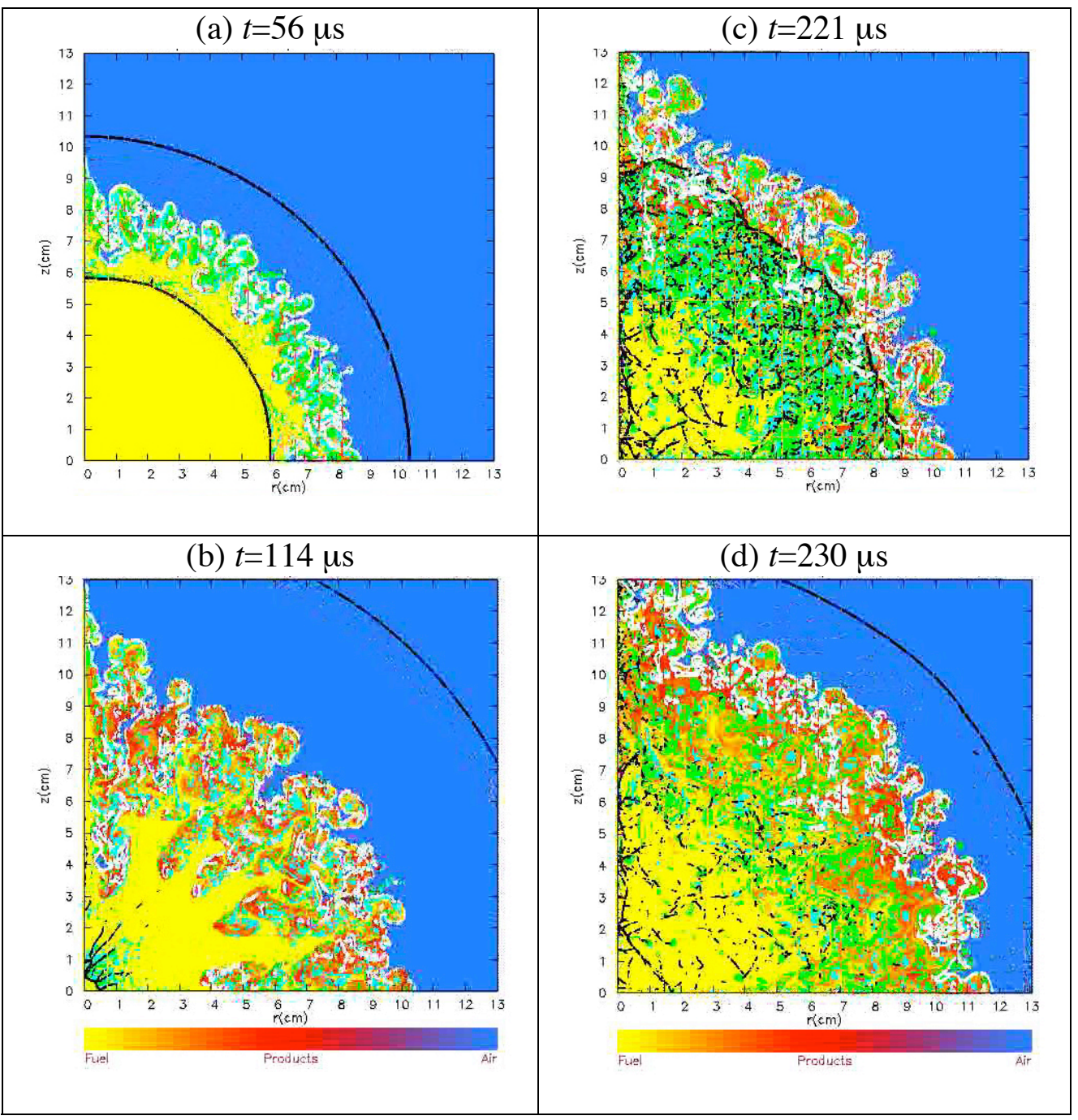

Figure 4. Evolution of turbulent mixing in a TNT fireball.

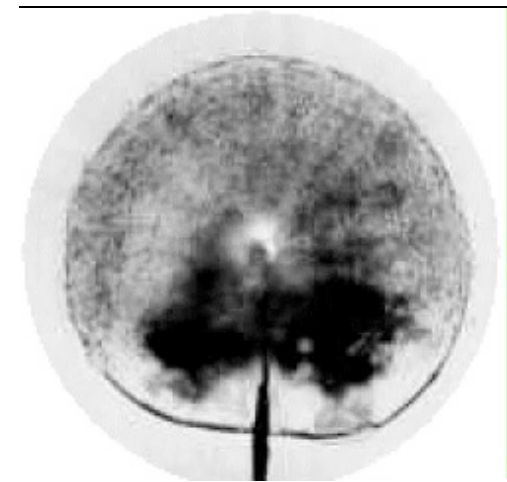

Figure 5. Shadow photograph of a PETN/TNT $(0.2 \mathrm{~g} / 0.5 \mathrm{~g})$ detonation products cloud.

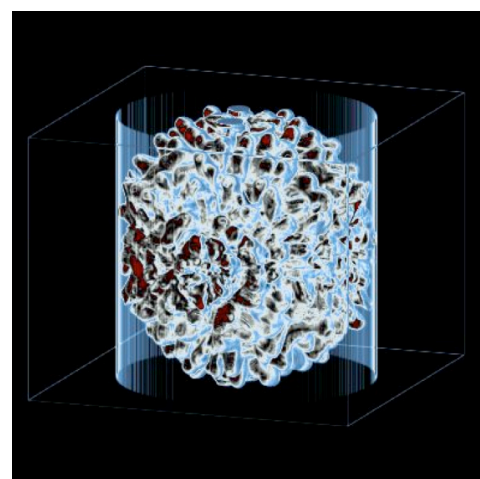

Figure 6. Combustion products surface from PETN/TNT charge $(0.5 \mathrm{~g} / 1 \mathrm{~g})$ in air. 


\section{COMBUSTION IN TNT EXPLOSIONS}

\section{COLOR PLATE 2}

Case A (6.6-liter calorimeter)

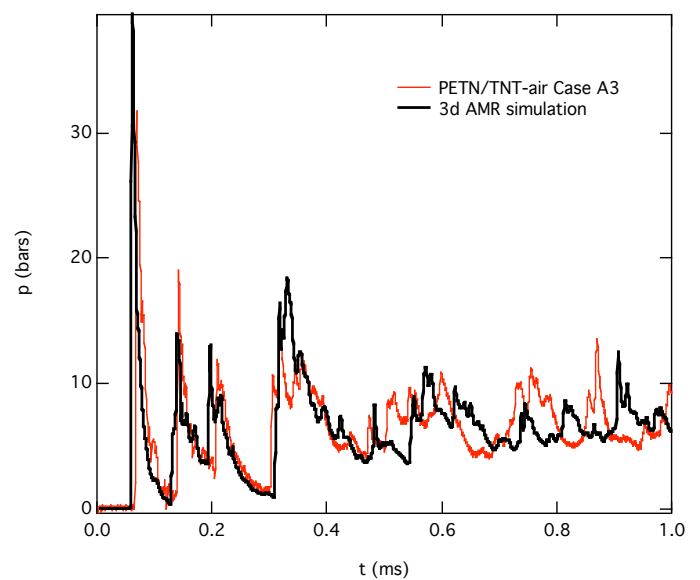

Case B (20.2-liter calorimeter)

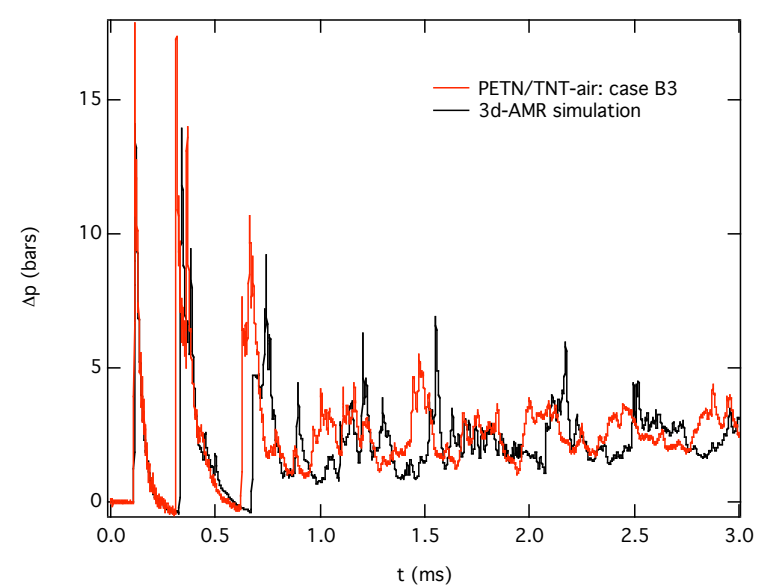

Case C (40.5-liter calorimeter)

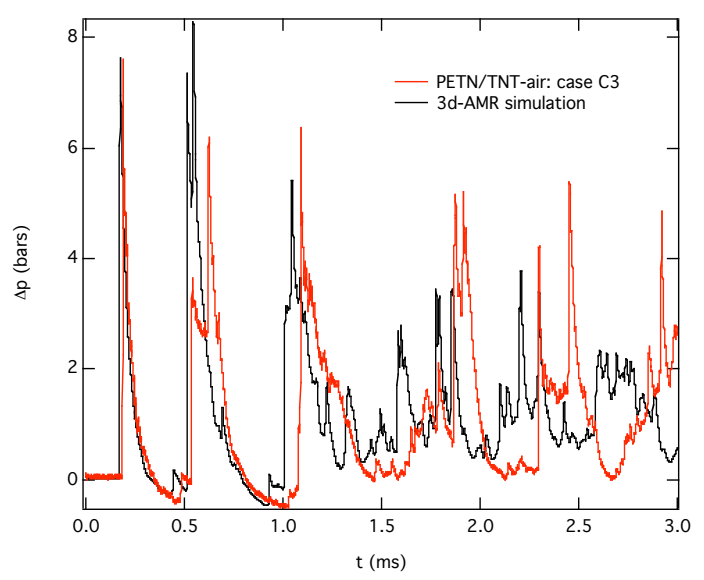

Case D (6.3-liter tunnel, $L / D=4.65)$

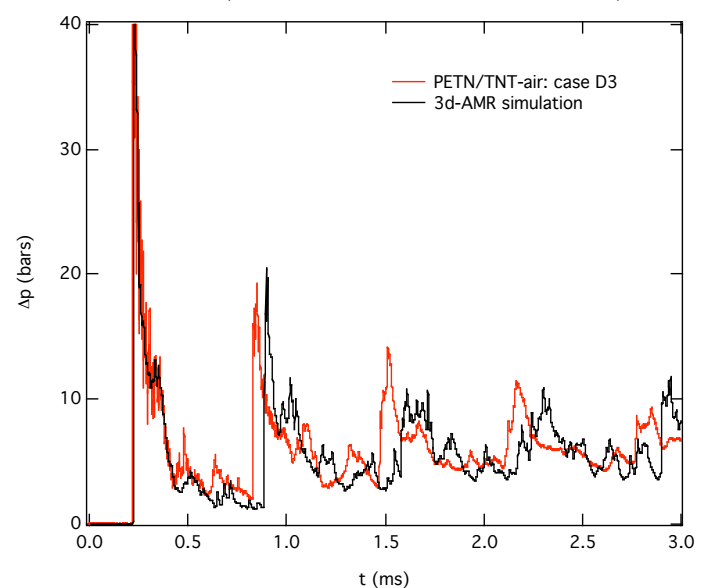

Case E (6.3-liter tunnel, $L / D=12.5)$

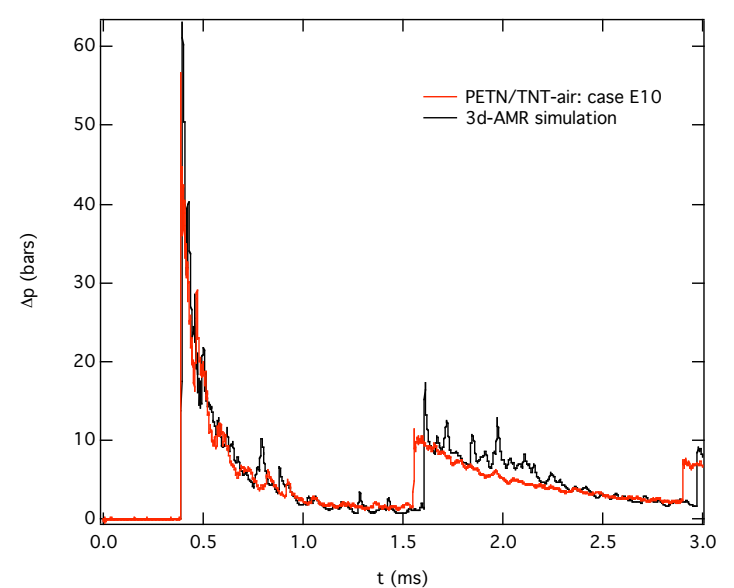

Case F (4-liter tunnel, $L / D=3.8$ )

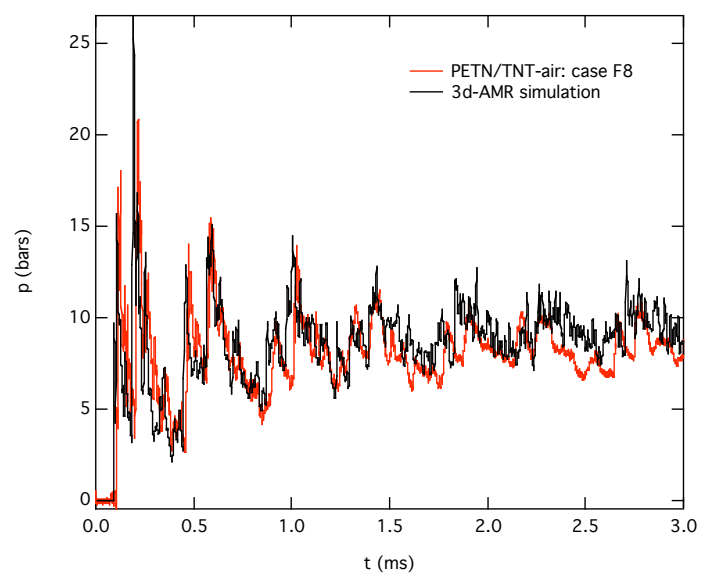

Figure 7. Comparison of pressure histories from numerical simulations with experimental data for explosion of 1.5-g PETN/TNT charges in cylindrical $(L / D=1)$ chambers with different volumes (Cases $\mathbf{A}, \mathbf{B}$ and $\mathbf{C}$ ) and tunnels with different $L / D$ ratios (Cases $\mathbf{D}, \mathbf{E}$ and $\mathbf{F}$ ). 